\title{
Ecophylogeography of Cassava Mosaic Disease Viruses Reveals a Distribution Linked to the Agro-ecosystems of Yangambi Region in Democratic Republic of Congo
}

\author{
Monde Godefroid ${ }^{1,4,}$, Walangululu Jean ${ }^{2}$, Winter Stephan ${ }^{3}$, Bragard Claude $^{4}$ \\ ${ }^{1}$ Agriculture University of Yangambi, Laboratory of Phytopathology, Kisangani, Democratic Republic of Congo \\ ${ }^{2}$ Catholic University of Bukavu, Faculty of Agriculture, Bukavu, Democratic Republic of Congo \\ ${ }^{3}$ Deutsche Sammlung von Mikroorganismen und Zellkuturen DSMZ GmbH, Plant Virus Collection, Braunschweig, Germany \\ ${ }^{4}$ Catholic University of Louvain, Earth \& Life Institute, Applied Microbiology - Phytopathology, Louvain-la-Neuve, Belgium
}

Email address:

mondekaz@yahoo.fr (M. Godefroid)

${ }^{*}$ Corresponding author

\section{To cite this article:}

Monde Godefroid, Walangululu Jean, Winter Stephan, Bragard Claude. Ecophylogeography of Cassava Mosaic Disease Viruses Reveals a Distribution Linked to the Agro-ecosystems of Yangambi Region in Democratic Republic of Congo. American Journal of Agriculture and Forestry. Vol. 9, No. 1, 2021, pp. 20-28. doi: 10.11648/j.ajaf.20210901.14

Received: December 26, 2020; Accepted: January 7, 2021; Published: January 15, 2021

\begin{abstract}
A molecular epidemiology study of cassava mosaic begomoviruses was conducted in Yangambi (DRCongo). 120 cassava fields were investigated in $150 \mathrm{Km}$ circle around the Agricultural Research Centre of Yangambi in various agroecosystems. Fields incidence and severity of CMD were scored, and whiteflies population counted per plant. 140 Cassava leaves samples, up to 100 weeds (Fabaceae) supposed to be alternate hosts of CMBs and 132 adults whiteflies were collected in cassava fields for molecular analysis. Targeted genes by PCR using specific primers were AC2 and AC4, which are the genes implied in the suppression of cassava mechanism of defence. Phylogeographical analysis of results showed that the virus distribution is linked to the agro-ecosystems. Moderate ACMV and EACMV-UG isolates associated with mild symptoms grouped in separate clusters based on a phylogenetic analysis of genes AC2 \& AC4. They were found in spatial discontinuous cassava cropping ecosystem lying in evergreen humid forest, and to a lesser extent, in permanent flood land and the deciduous high forest, where cassava crop is less intensive (disease severity $2.53 \pm 0.55$ ). In the more intensively cropped areas around cities and villages and the neighbouring secondary forest, the severe isolates were limited to spatial continuous cropping systems (disease severity $3.78 \pm 0.50$ ). Such results were also correlated with the mean number of whitefly per leaf or the incidence of disease. EACMV-UG isolates spread in the different ecosystems suggest multiple introductions of virus. Our study focused on the potential contribution of forest plants species diversity to mitigate the effect of CMD. The results showed also that CMD viruses are widely spread throughout the investigated area. Dual infection was common both in cassava $(66 \%)$ and in whiteflies vectors (59\%). The EACMV-UGSer was predominant, in relationship with highly infested fields.
\end{abstract}

Keywords: Cassava Mosaic Begomoviruses, Biodiversity-Stability, Agro-ecosystems, Spatial Discontinuous Cropping, Spatial Continuous Cropping

\section{Introduction}

Cassava mosaic disease (CMD) is considered as one of the major threat and a most devastating disease for cassava in Africa [1-3]. Dual infections with ACMV \& EACMV-UG are especially associated with severe CMD expansion through Africa [4-7]. This expansion is from Uganda to neighbouring countries like in Democratic Republic of Congo (DRCongo).

CMD associated begomoviruses have bipartite genomes with DNA components A \& B.

DNA A encodes for genes involved in the encapsidation (CP), the viral replication (AC1 and $\mathrm{AC} 3$ ), and the transcription activation (AC2) while DNA-B genes (BC1, $\mathrm{BV} 1)$ are involved in the cell-to-cell movement, host range and symptom modulation [6]. Differential roles of AC2 and 
AC4 of CMD viruses in the suppression of cassava mechanism of defence were largely described by Vanitharani et al. [8]. Such viruses are transmitted by whiteflies (Bemisia tabaci Gennadius - Hemiptera, Aleyrodidae) in a circulative manner [9-11]. Super-abundant whiteflies has been associated with the viral epidemic of CMD $[1,11]$.

For a long time, neighbouring populations of the stations of Agriculture Research of Yangambi have cultivated cassava as their major staple food crop in various agrosystems. Such crop is distributed in what is considered as one of the most diversified ecosystem in the world, in both spatial continuous or discontinuous cropping areas. CMD was also reported since 1929 in the DRCongo and later identified as caused by African cassava mosaic virus. Though variants of the severeassociated EACMV-UG have already been reported from DRCongo, both on East and West sides of the country [12]. Questions were raised about the presence and type of virus associated with CMD in such a hotspot for biodiversity.

The Yangambi forest is now a protected area into the Congo basin rainforest. Considering the "diversity stability hypothesis", one could expect that the impact of an outbreak like CMD would be less important in highly diverse agroecosystem than in areas where agricultural practice might reduce the ability of ecosystems to mitigate the effects of plants disease epidemic [13-15]. It also pointed out the possible impact of changing cropping practices on tropical plant viruses.

Around Yangambi, several ecosystems have been previously described as evergreen humid forest, mix secondary forest and deciduous high forest have driven to different systems of cassava grown. Spatial discontinuous system of cassava cultivation is practiced in the humid forest, contrariwise to the spatial continuous cropping system in the mix secondary forest. The micro climatic conditions and vegetation zones encountered in this region with such a diversity in cassava cultivation makes the area a suitable zone for studying the behaviour of CMD according to the cassava agro-ecosystem.

Indeed, other begomoviruses have already been studied in relationship to the agro-ecosystems where they are found. In Mediterranean basin around Spain and Italy, the high structuration of three isolates of Tomato Yellow leaf curl virus (TYLCV) has been described by Gracia- Andreas et al. [16]. Under the island "La Réunion", it was described a founder effect of TYLCV from a low initial genetic diversity among TYLCV-Mld [RE] isolates followed by moderate diversification of the virus population and by a linear increase in genetic diversity across years without geographical structuration in an insular environment [17].

In Pakistan, Ilyas et al. found a phylogeographical segregation between begomoviruses infecting legumes [18]. In Kenya, a phylogeography study showed differences in the type of EACMV found along the coastal Indian Ocean as compared to areas of higher altitude in Western and Central Kenya [19].
This study shows a differential distribution of both ACMV\&EACMV-UG according to their virulence as well as by systematic comparison of the sequences of the AC2/AC4 genes.

\section{Materials and Methods}

\subsection{Sampling}

Cassava leaves and cuttings (140 samples), up to 100 weeds or intercropped culture of species in Fabaceae family supposed to be alternate hosts of CMBs and 132 adults whiteflies (B. tabaci; Aleyrodidae, Hemiptera) were collected in cassava fields for molecular analysis. A total of 120 cassava fields were investigated in reason of 10 fields per village. Study area was $150 \mathrm{Km}$ circle around the Agricultural Research Centre of Yangambi as well as in the evergreen humid forest and in the mix secondary forest. Fabaceae species sampled were Arachis hypogaea L. 1753, C. pubescens Benth, Glycine $\max$ (L.) Merr. (soja) 1917, Leucaena leucocephala (Lam.) De Witt, 1961, Phaseolus vulgaris L. 1753, Psophocarpus scandens (Endl.) Verdc 1968 , P. javanica (Benth.) Benth 1864, Senna occidentalis (L.) Link1829, Vigna unguiculata (L.) Walp 1843and Vigna vexillata (L.) A. Rich 1845. Plants were selected on the basis of the presence of B. tabaci on their leaves or for the presence of mosaic symptoms on those leaves and their abundance in cassava fields as weeds or in intercropping systems. In cassava fields investigated, the incidence of CMD, the disease severity and the numbers of whiteflies per shoot were systematically evaluated. The severity was evaluated by scale from 1 to 5 used in IITA where 1: Symptom-free and 5: Severe chlorosis, leaf distortion and stunting [20]. The incidence was obtained in ratio to diseased plants and the total cassava plants. Whiteflies were counted and collected in the three first apical cassava leaves. Samples were brought in Plant Pathology laboratory, University catholic of Louvain (UCL), Belgium, for molecular analysis. Molecular data obtained after analysis were reported in the geographic map of Yangambi (Figure 1) provided by UCLGeomatics, UCL, Belgium.

\subsection{DNA Extraction, PCR Amplification and Sequencing}

DNA was extracted from plants leaves by using FastDNA ${ }^{\circledR}$ Kit with a FastPrep ${ }^{\circledR}$ Instrument (Q. Biogene, Inc., CA). The extract DNA was quantified by reading the absorbance (A) at 260/280 $\mathrm{nm}$ in Nanodrop. For whiteflies, DNA extraction has consist to crush five adults whitefly into a tube of $200 \mu \mathrm{l}$ in $50 \mu \mathrm{l}$ of TE buffer (Tris $\mathrm{HCl} 10 \mathrm{mM}$, pH 8 , EDTA $1 \mathrm{mM}$ ) and to heat at $90^{\circ} \mathrm{C}$ for $15 \mathrm{~min}$. The tube was then centrifuged at $13,000 \mathrm{trs} / \mathrm{min}$ to precipitate the debris. The supernatant was directly used as DNA for PCR. Specific nucleotides primers for AC2 and AC4 genes used in PCR were designed by Monde et al. [21]. 


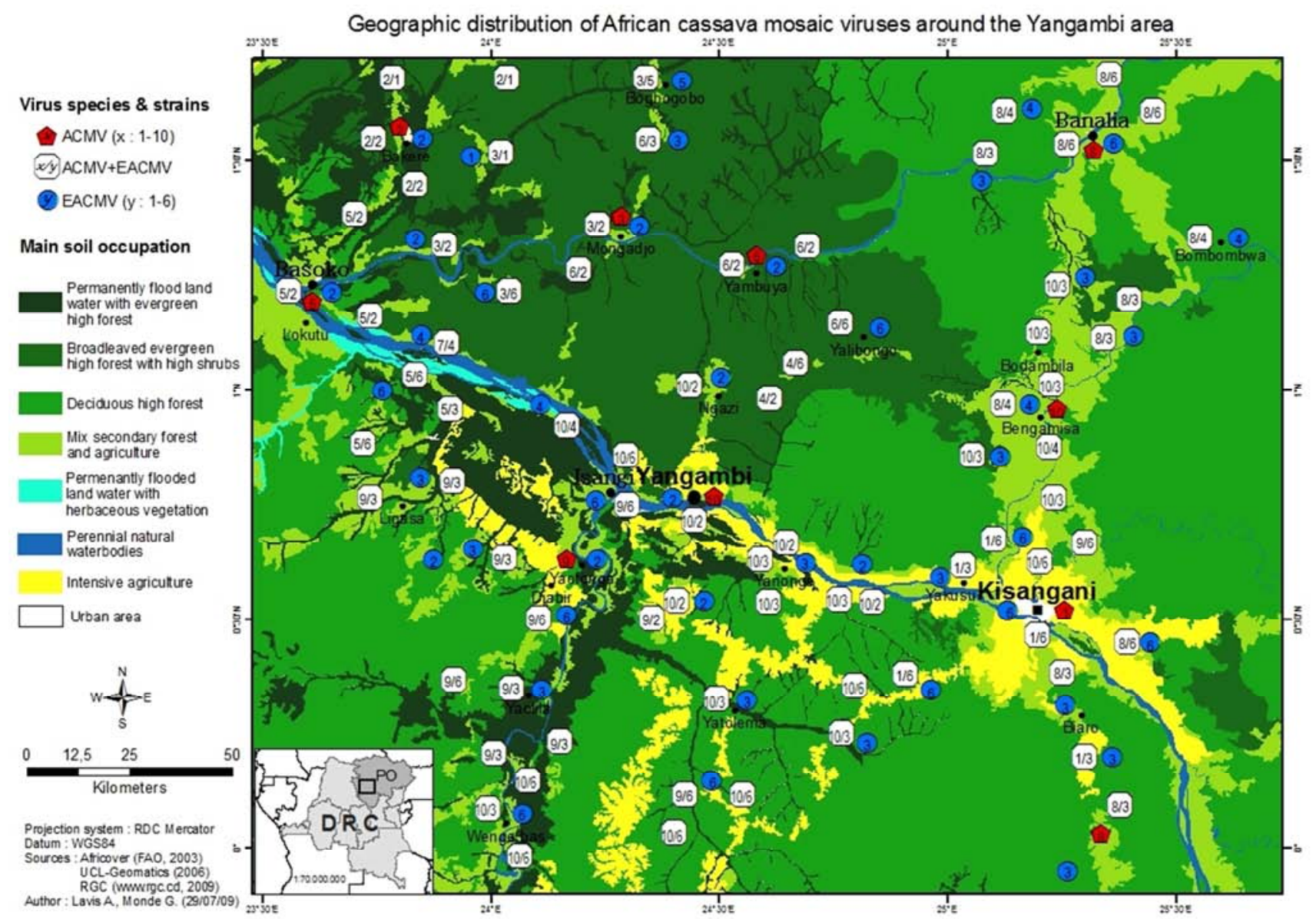

Figure 1. Geographic distribution of CMBs in function of agroecosystems in the Yangambi area. The locations of sampling were made in basis of the general card of DRCongo (UCL-Geomatics, Louvain-la-Neuve, Belgium). In a total of 140 cassava diagnosed, 10 different isolates of ACMV and 6 isolates of EACMV-UG were identified by molecular analysis in base of gene AC2 and AC4. The main isolates of ACMV are represented in the card by numbers indicating the following accessions 1: Ybil-FN435255 2: Ybi2-FN435256 3: Ybi3-FN435257 4: Ybi4-FN435258 5: Ybi5-FN435259 6: Ybi6-FN435260 7: Ybi7-FN435261 8: Ybi8-FN435262 9: Ybi9-FN435263 10: Ybil0-FN435264. For isolates of EACMV-UG, the following accessions were represented by numbers in the card 1: Ybi1-FN435265 2: Ybi2-FN4352663: Ybi3-FN435267 4: Ybi4-FN435268 5: Ybi5-FN435269 6: Ybi6-FN435270. Fractional numbers $(x / y)$ represent the dual infection of ACMV+EACMV-UG in the same sample collected in this location. The distribution of ACMV isolates is related to the principal agroecosystems and secondarily to the main circulation pathways. In the evergreen humid forest of Yangambi in which cassava cropping is in the spatial and temporal discontinuous system; the isolates 2: Ybi2-FN435256; 3: Ybi3-FN435257; 4: Ybi4-FN435258; 5: Ybi5-FN435259; 6: Ybi6-FN435260 and 7: Ybi7-FN435261 are restricted; whereas in the secondary forest zone in which cassava is in a non-discontinuous intensive cultivation the main isolates spread are 1: Ybil-FN435255; 8: Ybi8-FN435262; 9: Ybi9-FN435263 and 10: Ybi10-FN435264. EACMV-Ybil and EACMV-Ybi5 are adapted in the evergreen forest; other EACMV-UG isolates are randomly spread as well in primary forest as in the mix secondary forest.

The mix PCR was prepared in a final volume of $50 \mu \mathrm{l}$ using $\mathrm{H}_{2} \mathrm{O}$ depec $26.25 \mu \mathrm{l}, \mathrm{MgCl}_{2} 25 \mathrm{mM} 5 \mu \mathrm{l}$, GoTaq ${ }^{\circledR} 5 \mathrm{x}$ flexi buffer $10 \mu \mathrm{l}$, DNTP $100 \mathrm{mM} 1.5 \mu \mathrm{l}$, each upstream and downstream primer $1 \mu$ l, GoTaq ${ }^{\circledR}$ DNA polymerase (Promega) 5 units $/ \mu 10.25 \mu$, extract DNA $5 \mu l$.

The PCR was cycling by a thermocycler iCycler Biorad $\AA$ version 4.006 at $94^{\circ} \mathrm{C}$ for 2 min for denaturizing, followed of 38 cycles of amplification at $94^{\circ} \mathrm{C}$ for $30 \mathrm{sec}$ for denaturizing; hybridization at $58^{\circ} \mathrm{C}$ for $30 \mathrm{sec} ; 72^{\circ} \mathrm{C}$ for $1 \mathrm{~min}$ for elongation. The final elongation has been done at $72^{\circ} \mathrm{C}$ for 7 min. The revelation was made in $1.2 \%$ agarose gel under UV after electrophoresis at $120 \mathrm{~V}$ in ethidium bromide.

Partial sequences produced from Biosequencer Genetic Analyser 3100 after direct sequencing were assembled using the software Vector NTI ${ }^{\circ}$ Advance11 (Invitrogen). Each amplicon was sequenced many times forward and reverse.

Nucleotides sequence was translated in amino acids by a molecular toolkit (www.vivo.colostate.edu). The expressed mutations in amino acids sequences are shown in front of respective phylogenetic trees by alignment (Figure 2, Figure 3).

Phylogenetic trees were carried out by using MEGA4.1 Software based on concatenated amino acids sequences of AC2 \& AC4 of CMBs isolates available in NCBI GenBank, that included the concatenated amino acids sequences of $\mathrm{AC} 2$ \& AC4 of $\mathrm{CMBs}$ isolated from Yangambi [22]. The evolutionary history was determined using the NeighbourJoining method with the complete deletion option and 1000 replicates for bootstrap values. 


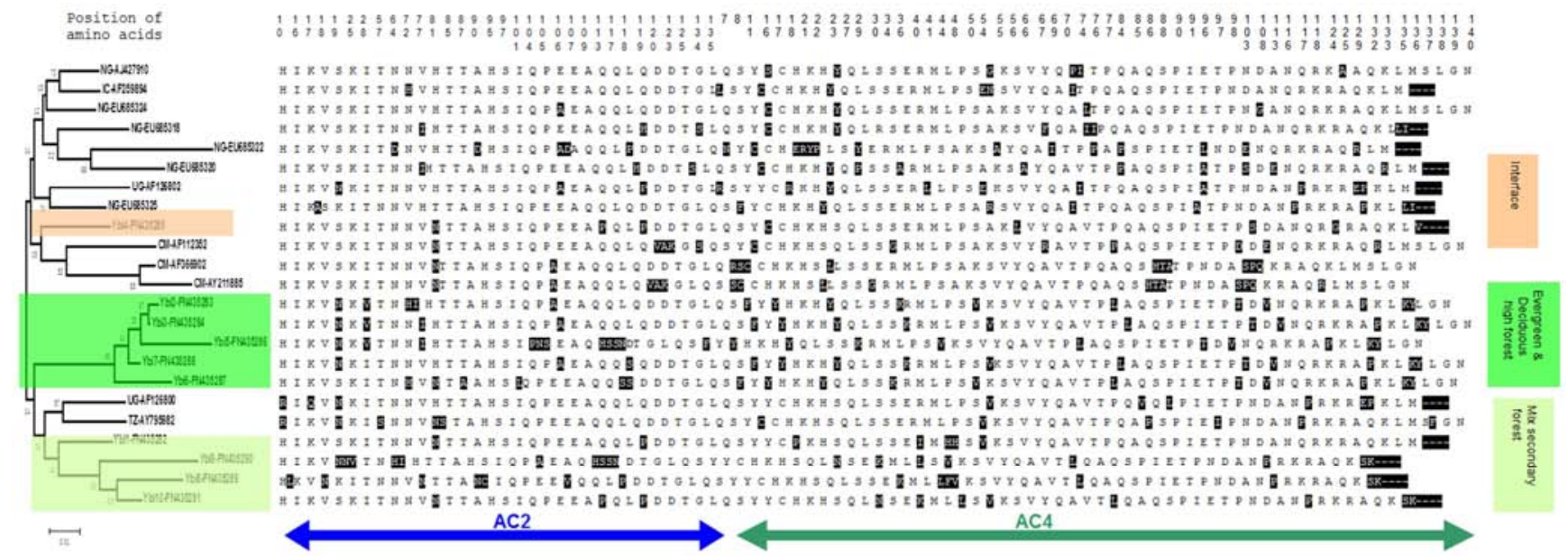

Figure 2. Phylogenetic tree based on concatenated sequences of amino acids of genes AC2 and AC4 for ACMV inferred from the neighbour-joining method using MEGA Software version 4.1 with complete deletion option (ClustalW). Bootstrap values (1000 replicates) are shown as percentages in the branches (Tamura et al., 2007). The isolates Ybil-10 are the different isolates of ACMV identified from Yangambi region in the accessions beginning by FN; UG: Uganda; CM: Cameroon, NG: Nigeria \& TZ: Tanzania. The isolates of Yangambi are clustering in 3 groups: the first cluster regroups isolate Ybi4 \& others in the interface, the second consists to 4 isolates (Ybil, 8, 9, 10) which have a premature codon stop in gene AC4 closely related to the mix secondary forest; the third consists to five isolates Ybi2, 3, 5, 6, 7 which have formed an apart cluster related with the evergreen forest.

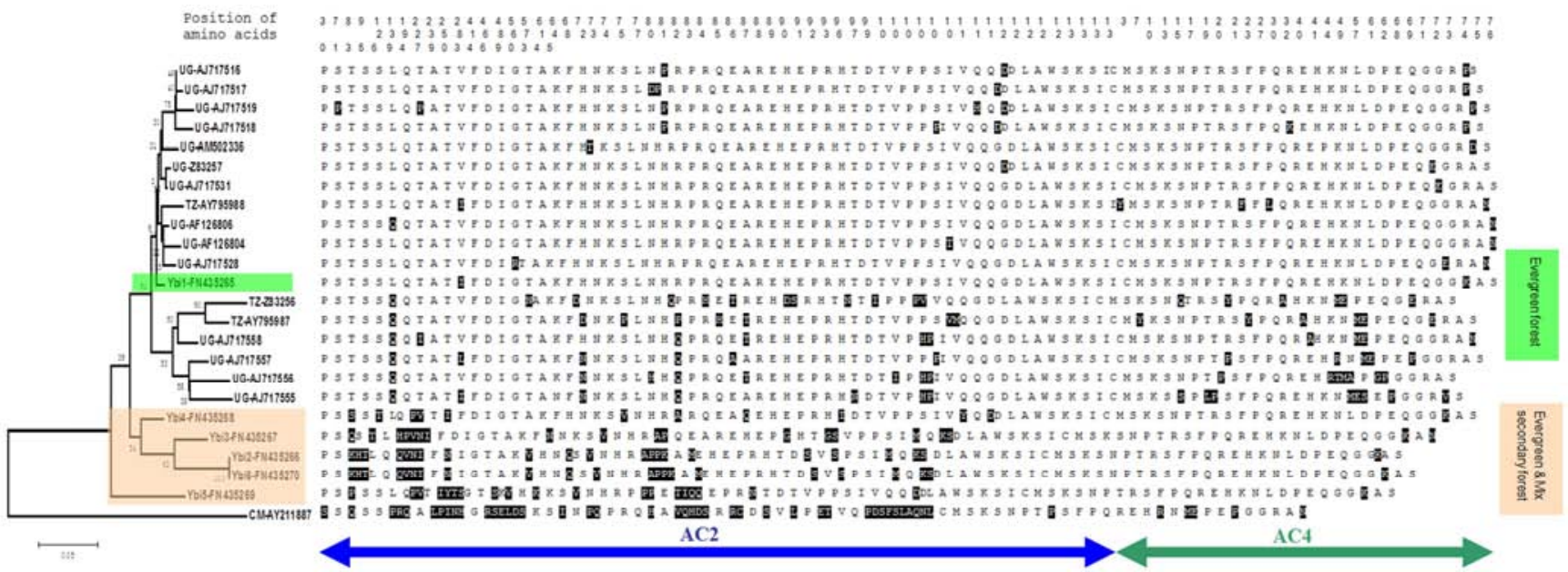

Figure 3. Phylogenetic and molecular analyse based on amino acids in concatenated sequence of genes AC2 and AC4 for EACMV-cassava virus positive inferred from the Neighbour-joining method using MEGA version 4.1 with complete deletion option. Bootstrap values (1000 replicates) are shown as percentages in the branches (Tamura et al., 2007). The isolates Ybi 1-6 are the EACMV isolates identified in cassava from Yangambi which the accessions begin by FN; also UG: Uganda; TZ: Tanzania. The strains of Yangambi are clustered with Ugandan and Tanzanian strains. The isolates from Yangambi have formed 2 clusters indicating the presence of 2 major strains of EACMV associated in CMD. In the phylogenetic tree, 5 isolates from Yangambi FN435266, FN435267, FN435268, FN43569 and FN435270 have presented an apart cluster and they have shown much expressed mutations in amino acids sequences. The isolate FN435265 has presented the proximity with Tanzanian and Ugandan's strains. It may be the presence of 2 main strains of EACMV-UG which involve in epidemic of CMD in Yangambi.

\section{Results}

\subsection{Dual Infection by CMD-viruses Is Common in Yangambi}

The investigations in principal agro-ecosystems showed the presence of a largest proportion of dual infection (66\%), followed by infection in EACMV-UG (26\%) and by infection in ACMV (5\%) in cassava. 3\% of cassava sampled were CMDvirus free. A high percentage of adults whiteflies infected viruses was also found in the similar proportions ACMV+EACMV-UG (59\%), EACMV-UG (29\%) and ACMV
$(8 \%)$. Only a few $(4 \%)$ of the whiteflies tested were virus-free in the Yangambi area. Furthermore, both viruses ACMV \& EACMV-UG were detected in dual infection in Centrosema pubescens Benth and Pueraria javanica (Benth) Benth (Fabaceae) developing the same symptoms as CMD, raising the question of a possible involvement of those leguminous in the CMD pathosystem $[2,21,23]$. This confirms that the spread of CMBs in double infection as a general phenomenon [11].

Our study underlines the prevalence of EACMV-UG and its largely spread in Yangambi (data not shown). The CMD severity scores and the incidence registered in these locations (Table 1) indicate that the strains in secondary forest are aggressive. The high number of whiteflies encountered in the mix secondary forest 
(Table 1) might explain the high incidence and severity of CMD registered in this intensive cassava cultivation zone. These results corroborate those obtained by Legg and Thresh in East Africa and by Ariyo et al. in Nigeria [24, 25].

Table 1. Relationship between agroecosystems, CMD severity\& incidence, whiteflies abundance and CMD-viruses in the region of Yangambi. The accessions of both begomoviruses infecting cassava in the Yangambi region are listed. High disease severity scores [3-5] of CMD is noted in the secondary forest where cassava cultivation is intensive. In the deciduous forest and in the evergreen forest, the disease severity scores varied between [2-3].

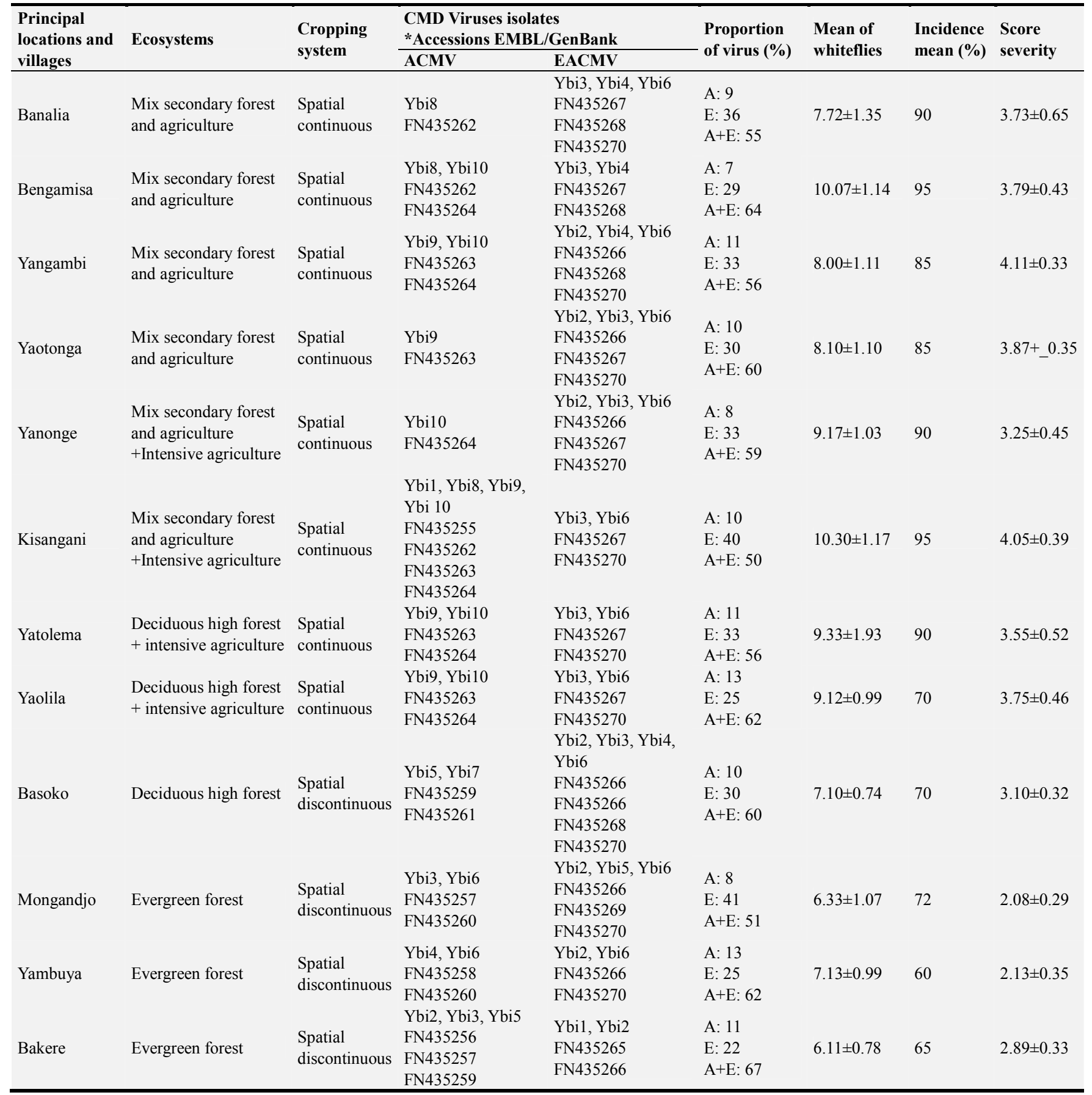

Legend:

A: single infection ACMV E: single infection EACMV-UG A+E: dual infection with ACMV and EACMV-UG

Score severity: $1-5$; where 1: indicates no symptom and 5: severe symptom

*The accessions numbers are related to the number in the CMBs molecular distribution in Figure 1

\subsection{Cassava Mosaic Disease Severity Is Related to the Agro-ecosystems}

CMD is widespread in the North-Eastern DRCongo
(Figure 1); its distribution is related to the principal ecosystems and to the main circulation ways. However, CMD severity, incidence as well as the whiteflies frequencies are closely related to the various agro-ecosystems in the 
Yangambi area (Table 1, Figure 1). In a general manner, the more diverse the ecosystem, the less severe is the cassava mosaic disease. The CMD is moderate in the evergreen forest near the localities of Bakere, Yambuya and Mongandjo, where agricultural activity is less intensive. In these evergreen forest localities dominated by a spatial discontinuous cassava cultivation, the disease severity was $2.37 \pm 0.32$, with an incidence varying from $60-72 \%$. Presence of whiteflies vector is also limited (mean number of whiteflies 6.52 \pm 0.94$)$.

In the deciduous high forest near Basoko, where cassava is less intensively cultivated in a spatial discontinuous system, CMD severity was intermediate $(3.10 \pm 0.32)$ associated with a less number of whiteflies $(7.10 \pm 0.74)$ and an incidence of $70 \%$.

However, CMD displays a higher impact in terms of severity in the deciduous high forest near Yatolema (3.55 \pm 0.52$)$ and in Yaolia (3.75 \pm 0.46$)$ localities where cassava culture is intensively practiced in a spatial continuous system. A higher disease incidence (70-90\%) and number of whiteflies vector varying from $9.12 \pm 0.99$ to $9.33 \pm 1.93$ were also registered (Table 1 ).

The disease is even more severe in the mix secondary forest such as Banalia, Bengamisa, Yangambi, Yaotonga and Yanonge localities where cassava crop is more intensive in spatial continuous system ( disease severities ranged from $3.25 \pm 0.45$ to $4.11 \pm 0.33$ ). This high disease severity was associated with higher whiteflies number (number of whiteflies vector $7.72 \pm 1.35$ to $10.07 \pm 1.14$ ) and a disease incidence between $85-95 \%$ according to the location.

However, around the Kisangani locality, where cassava production is also the more intensive in spatial continuous cropping system, the severity and incidence of CMD recorded were the highest, respectively $4.05 \pm 0.39$ and $95 \%$, and also associated with high whiteflies number $10.30 \pm 1.17$.

\subsection{Cassava Mosaic Begomoviruses Reveal an Ecophylogeographically Distribution in Yangambi}

All sequences for AC2 \& AC4 from ACMV/EACMV-UG have been listed in EMBL nucleotides database as following accessions FR675645 to FR675825 (180 accessions) and FN435255 to FN435297 (42 accessions). From these sequences, ten different types of ACMV and six different types of EACMV-UG were identified (Table 1).

The ACMV-isolates Ybi2-FN435256, Ybi3-FN435257, Ybi5-FN435259, Ybi6-FN435260 and Ybi7-FN435261 are restricted to the evergreen forest and in the deciduous forest encountered in the localities of Bakere, Yambuya, Mongandjo and Basoko where cassava is cultivated in a spatial discontinuous system (Table 1, Figure 1). However Ybi4-FN435258 was found at the interface between mix secondary forest and evergreen forest (Figure 1, Figure 2). Those isolates induced a less severe cassava mosaic. They were found with the lowest incidence of CMD in the area. The ACMV isolates Ybil-FN435255, Ybi8-FN435262, Ybi9-FN435263 and Ybi10-FN435264 (Table 1, Figure 1) were found globally in the mix secondary forests and/or deciduous high forests in Banalia, Bengamisa, Kisangani, Yangambi, Yaotonga, Yatolema, Yanonge and Yaolila, where cassava crop and agriculture activity are intensive in a spatial continuous cropping system. The isolates ACMVYbi4 and ACMV-Ybi7 were identified systematically in double infection exclusively at the boundaries of forest in interface with the mix secondary forest.

Nevertheless, the EACMV-UG isolates Ybil-FN435265 and Ybi5-FN435269 were restricted only to the evergreen forest in Bakere and Mongandjo. This specific restriction indicates that these EACMV-UG isolates have been adapted in the primary forest ecosystem. These results corroborate a phylogeographical segregation which was reported between three distinct groups of Mungbean yellow mosaic indian virus (Begomovirus) infecting legumes in Pakistan. The first type occurs across the country, whereas the second type has only been identified in the North of Pakistan; the third type was a recombinant between both [18].

\subsection{Diversity of Cassava Mosaic Disease Viruses Using Genes $A C 2$ and $A C 4$}

The molecular analysis indicates less diversity in all CMBs strains isolated; only 10 isolates of ACMV-(Ybil-10) and 6 isolates of EACMV-UG-(Ybi1-6) were found in the Yangambi region. The reduced diversity of CMD viruses observed in Yangambi conflicts other studies conducted in Africa [6, 25] which reported a high diversity of CMBs strains in CMD epidemic in East Africa. This low diversity of CMBs strains identified was spread according to the various ecosystems (Figure 1). The EACMV-UG Ybi1 and Ybi5 restricted into the evergreen forest suggest their adaptation in the primary forest ecosystem or an introduction occurring before the others.

The phylogenetic trees established based on concatenated amino acids of genes AC2 \& AC4 showed the presence of ten isolates of ACMV segregated in two clusters (Figure 2) and six isolates of EACMV-UG clustered in two mains groups (Figure 3). The first ACMV isolates cluster with truncated AC4 gene presenting a premature codon stop is found associated with more severe disease in cassava in the intensively cropped cassava area around Yangambi dominated by the mix secondary forest and the deciduous high forest (Figure 2). The second cluster with entire AC4 was linked to moderate $\mathrm{CMD}$ in the evergreen forest. For EACMV-UG isolates (Figure 3), the first cluster is limited in evergreen forest and the second cluster is spread as well in evergreen forest as in mix secondary forest. High expressed mutations in amino acids sequences of AC2 have been displayed by this CMBs group.

\section{Discussion}

Phylogeography showed a distribution of CMBs and CMD severity closely related to the agro-ecosystems where cassava is grown and to the main circulation pathways (Figures 1, 2, 3). The high CMD severity recorded in the mix secondary forest and in the deciduous high forest might 
be due to the abundance of populations of whiteflies, in opposite to the moderate disease in the evergreen forest that might be due to a relatively less number of whiteflies. Abundance whiteflies might result to optimal development conditions in mix secondary forest considering the continuous cassava crop practice used; whereas biological control by predator in the primary forest might reduce populations of whiteflies [26].

The present study showed a clear link between highly diverse ecosystems and less severe impact of CMD in the Yangambi region. This result supports the diversity stability hypothesis concept considering that ecosystems with more species may minimize the effects of environmental disturbances such as plants disease epidemic [13-15]. Given agricultural practices can reduce the ability of ecosystems to mitigate the effects of plants disease epidemic in an ecosystem $[13,14]$; the high CMD severity observed in mix secondary forest might be consecutive to the intensive spatial continuous cultivation of cassava and to the reduced biodiversity in this agro-ecosystem.

The low diversity of CMBs strains identified was spread according to the various ecosystems (Figure 1); however the pattern of evolution of EACMV-UG isolates in evergreen forest suggests multiple introductions. In the evergreen humid forest area, the localised spread of CMBs might be explained by the spatial discontinuous of cassava cultivation system in the humid forest where geographical barrier imposed by no-cultivated area might prevent the movement of viruliferous insects between agro-ecosystems. Natural biological control of whiteflies is also hypothesised to explain the less number recorded in evergreen humid forest area [26], though data are still lacking in this area. Contrariwise in the mix secondary forest where the spatial continuous cropping system of cassava is practiced and abundant whiteflies movement is not limited. Infected cuttings flux was probably intense.

As AC2 \& AC4 genes act in PTGS suppressing, variation in their sequences might have significance in CMD epidemic $[8,27]$. So truncated AC4 might result from diversification and evolution of CMD viruses and probably contribute to their virulence [19]. Similar observations were also made on TYLCV in the insular environment of Réunion where truncated AC4 protein for four amino acids had driven to evolution and diversification of virus [17].

Dual infection in native legumes suggests that whiteflies might infect non-cassava plants when there is high epidemic pressure. CMD viruses were also found in various native species in Africa [28-30]. Since begomoviruses can be easily transmitted between cassava and non-cassava by their whitefly vector, thereby facilitating the survival of viruses and their concentration in environment. Other begomoviruses like Mungbean yellow mosaic virus with agricultural significance were identified in cultivated grain legumes in Pakistan [18]. The presence of those Legumes yellow mosaic viruses (begomoviruses) and the CMBs in native or cultivated legumes raises question of their probable recombination? As the role of those native legumes is not clearly specified in CMD pathosystem until now, one hypothesizes that selection by host plants may orientate the diversification of virus and may drive to the evolution of CMD viruses. Various selection pressures operating in plant viruses will differ depending on plant host and vector population [31-33]. Mixed infections can also have an effect through viral interactions. The frequency of mixed infections and recombination are well known processes that contribute to begomoviruses diversification and evolution [7, 34-36]. The random spread of some EACMV-UG isolates in both agro-ecosystems hypothesized a preferential transmission of EACMV-UG by whiteflies $[11,25]$. The prevalence of EACMV-UG well known in Uganda epidemic [7], associated to sensitive genotypes [37] led to consider Yangambi as a potential CMD epidemic zone according to $[2,12]$. Thus, the CMBs distribution is related to the agro-ecosystems in NorthEastern DRCongo; also the biodiversity richness in agroecosystems is evident in the mitigation of CMD.

\section{Conclusion}

The present study focused on the potential contribution of forest'plants species diversity to mitigate the effect of CMD. Results showed a clear link between highly diverse ecosystems and less severe impact of CMD in the Yangambi region. Those results support the diversity-stability hypothesis considering that ecosystems with more species may minimize the effects of environmental disturbances such as plants disease epidemic. It is clearly highlighted that the more diverse the ecosystem, the less severe is the cassava mosaic disease. Furthermore, the fact that dual infection was common as well in cassava as in native legumes suggests that whiteflies might infect non-cassava plants when there is high epidemic pressure.

\section{Conflict of Interest}

The authors declare no conflict of interest for this study.

\section{Acknowledgements}

This study was funded through a Belgian Technical Cooperation scholarship. Study was conducted in the Laboratory of Phytopathology at Catholic University of Louvain and the Agriculture University of Yangambi in DRCongo. Authors are grateful to UCL-ENGE- Geomatics for providing kindly the map of Yangambi.

\section{References}

[1] Bisimwa E. B., Birindwa D. R., Yomeni M. O., Rudahaba N., Byamungu K., Winter S. and Bragard C. (2019) Multiple cassava viruses' co-infections and resurgence of pests are leading to severe symptoms and yield losses on cassava in the South-Kivu region, Democratic Republic of Congo. Amer J of Plant Sci 10: 1969-1988. 
[2] Legg, J. P., Lava Kumar, P., Makeshkumar, T., Tripathi, L., Ferguson, M., Kanju, E., Ntawuruhunga, P. \& Cuellar, W. (2015): Cassava virus diseases: Biology, epidemiology, and management. Pages 85-142 in: Control of Plant Virus Diseases - Vegetatively-Propagated Crops. G. Loebenstein and N. I. Katis, eds. Advances in Virus Research, Vol. 91. Elsevier Inc., Kidlington, Oxford, UK.

[3] Alabi J., Kumar L. and Naidu A. (2011): Cassava mosaic disease: A curse to food security in Sub-Saharan Africa. APSnet Features.

[4] Monde G., Walangululu J. and Bragard C. (2012) Screening cassava for resistance to cassava mosaic disease by grafting and whitefly inoculation. Arch of Phytopathol and Plant Protection, vol 45, 2189-2201.

[5] Basavaprabhu, L., Patil and Fauquet, C. M. (2009) Cassava mosaic geminiviruses: actual knowledge and perspectives. Mol Plant Pathol 10 (5): 685-701.

[6] Ndunguru, J., Legg, J. P., Aveling, T. A. S., Thompson, G. and Fauquet, C. M. (2005) Molecular biodiversity of cassava begomoviruses in Tanzania: evolution of cassava geminiviruses in Africa and evidence for East Africa being a center of diversity of cassava geminiviruses. Virol J 2: 21. doi: $10.1186 / 1743-422 \mathrm{X}-2-21$

[7] Zhou, X., Liu, Y., Calvert, L., Munoz, C., Otim-Nape, G. W., Robinson, D. and Harrison, B. D. (1997) Evidence that DNAA of a geminivirus associated with severe cassava mosaic disease in Uganda has arisen by interspecific recombination. $\mathrm{J}$ Gen Virol 78: 2101-2111.

[8] Vanitharani, R., Padmanabhan, C., Pita, J. S. and Fauquet, C. M. (2004) Differential roles of AC2 and AC4 of Cassava Geminiviruses in mediating synergism and suppression of posttranscriptional gene silencing. J Virol 78 (17): 9487-9498.

[9] Njoroge, M. K., Mutisya, D. L., Miano, D. W. and Kilalo D. C (2017) Whitefly species efficiency in transmitting cassava mosaic and brown streak virus diseases. Cogent Biology, 3, 1311499 .

[10] Maruthi, M. N., Jeremiah, S. C., Mohammed, I. U., and Legg, J. P. (2017) The role of the whitefly, Bemisia tabaci (Gennadius), and farmer practices in the spread of cassava brown streak ipomoviruses. Journal of Phytopathology, 165: 707-717.

[11] Colvin, J., Omongo, C. A., Maruthi, M. N., Otim-Nape, G. W. and Thresh, J. M. (2004) Dual Begomovirus infections and high Bemisia tabaci populations: two factors driving the spread of a cassava mosaic pandemic. Plant Pathol 53: 577584.

[12] Legg, J. P., Owor, B., Sseruwagi, P. and Ndunguru, J. (2006) Cassava mosaic viruses disease in East and Central Africa: epidemiology and management of a regional pandemic. Adv Virus Res 67: 355-418.

[13] Tilman, D., Reich, P. B. and Knops, J. M. H. (2006) Biodiversity and ecosystem stability in a decade-long grassland experiment. Nature 44 (1): 629-632.

[14] Tilman, D., Cassman, K. G., Matson, P. A., Naylor, R. and Polasky, S. (2002) Agricultural sustainability and intensive production practices. Nature 418: 671-677.

[15] Hooper, D. U, Chapin, F. S, Ewel, J. J., Hector, A., Inchautsi, P., Lavorel, S. et al. (2005) Effects of biodiversity on ecosystem functioning: a consensus of current knowledge. Ecol Monographs 75 (1): 3-35.

[16] Garcia-Andreas S., Accotto G. P., Castillo J. N. and Moriones E. (2007) Founder effect, plant host and recombination shape the emergent population of begomoviruses that cause the Tomato yellow leaf curl disease in the Mediterranean basin. Virology 359: 302-312.

[17] Delatte H., Holota H., Moury B., Reynaud B., Lett J. M. and Peterschmitt M. (2007) Evidence for a Founder effect after introduction of Tomato yellow leaf curl virus-Mild in an insular environment. J Mol Evol 65: 112-118.

[18] Ilyas, M., Qazi, J., Mansoor, S. and Briddon, R. W. (2010) Genetic diversity and phylogeography of begomoviruses infecting legumes in Pakistan. J Gen Virol 91 (8): 20912101.

[19] Bull, S. E., Briddon, R. W., Sserubombwe, W. S., Nugi, K., Markham, P. G. and Stanley, J. (2006) Genetic diversity and phylogeography of cassava mosaic viruses in Kenya. J Gen Virol 87: 3053-3065.

[20] Hahn, S. K., Terry, E. R. and Leuschner, K. (1980) Breeding cassava for resistance to cassava mosaic disease. Euphytica 29: 673-683.

[21] Monde, G., Walangululu, J., Winter, S. and Bragard, C. (2010) Dual infection by cassava begomoviruses in two leguminous species (Fabaceae) in Yangambi, North-Eastern Democratic Republic of Congo. ArchVirol, doi 10.1007/s00705-0100772-3.

[22] Tamura, K., Dudley, J., Nei, M. and Kumar, S. (2007) MEGA4 Molecular Evolutionary Genetics Analysis (MEGA) software version 4.0. Mol Biol Evol 24: 1596-1599.

[23] Shirima, R., Maeda, D. G., Kanju, E. E., Tumwegamire, S., Ceasar, G., Mushi, E., Sichalwe, C., Mtunda, K., Mkamilo, G., and Legg, J. P. (2019) Assessing the degeneration of cassava under high virus inoculum conditions in Coastal Tanzania. Plant Disease, 103: 2652-2664.

[24] Legg, J. P. and Thresh, J. M. (2000) Cassava mosaic virus disease in East Africa: a dynamic disease in a changing environment. Virus Res 71: 135-149.

[25] Ariyo, O. A., Koerbler, M., Dixon, A. G. O., Atiri, G. I. and Winter, S. (2005) Molecular variability and distribution of cassava begomoviruses in Nigeria. J Phytopathol 153: 226 231.

[26] Tscharntke, T., Klein, A. M., Kruess, A., Steffa-Dewenter, I. and Thies, C. (2005) Landscape perspectives on agricultural intensification and biodiversity: ecosystem service management. Ecol Letters 8: 857-874.

[27] Vanitharani, R., Chellapan, P., Fauquet, C. M. (2005) Geminiviruses and RNA silencing. Trends Plant Sci 10 (3): 144-151.

[28] Alabi, J. O., Ogbe, F., Bandyopadhyay, R. and Lava Kumar, P. (2008) Alternative hosts of African cassava mosaic virus and East African cassava Cameroon virus in Nigeria. Arch Virol 153: 1743-1747.

[29] Ogbe, F. O., Dixon, A. G. O., Hughes, J. A., Alabi, O. J. and Okechukwu, R. (2006) Status of cassava begomoviruses and their new natural hosts in Nigeria. Plant Dis 90: 548-553. 
[30] Shonyika, S. A., Thottappily, G., McGrath, F. and Harrison, B D. (2001) Detection, relationships and properties of cassava mosaic Geminivirus in naturally infected castor oil plant, Ricinus communis L. in Nigeria. Page 20 in: The book of abstracts, Fifth Conf. Cassava Biotech. Network (CBN-V), Donald Danforth Plant Science Center, St. Louis.

[31] Garcia-Arenal, F., Fraile, A. And Malpica, J. M. (2003) Variation and evolution of plant viruses populations. Int Microbiol 6: 225-232.

[32] Garcia-Arenal, F., Fraile, A. And Malpica, J. M. (2001) Variability and genetic structure of plant viruses populations. Ann Rev Phytopathol 39: 157-186.

[33] Harrison, B. D. (2002) Virus variation in relation to resistancebreaking in plants. Euphytica 124: 181-192.

[34] Varsani, A., Monjana, A. L., Donaldson, L., Oluwafemi, S., Zinga, I., Komba, E. K. et al.(2009) Comparative analysis of
Panicum streak virus and Maize streak virus diversity, recombination patterns and phylogeography. Virol J6: 194 doi 10.1186/1743-422x-6-194.

[35] Fondong, V. N., Pita, J. S., Rey, M., De Konchko, A., Beachy, R. N. and Fauquet, C. M. (2000) Evidence of synergism between African cassava mosaicvirus and a new doublerecombinant geminivirus infecting cassava in Cameroon. J Gen Virol 81: 287-297.

[36] Sanz, A. I., Fraile, A., Gracia-Arenal, F., Zhou, X., Robinson, D. J., Khalid, S., et al. (2000) Multiple infection, recombination and genome relationships among begomovirus isolates found in cotton and other plants in Pakistan. J Gen Virol 81: 1839 -1849.

[37] Ngeve, J. M., Nukenine, E. N. and Dixon, A. G. O. (2003) Reaction of genotypes to the cassava mosaic disease in three district agroecologies in Nigeria. J. Phytopathol 151: 101-107. 